\title{
SEXUALIDADE, SEGURANÇA E DISCIPLINA: CORPO E DISCURSO FÍLMICO EM “REFORMATÓRIO DAS DEPRAVADAS” (1978), DE ODY FRAGA
}

\author{
Tyrone Coutinho Chaves Filho* \\ Nilton Milanez*
}

RESUMO: Nosso intuito, com esse artigo, é problematizar o corpo em meio às relações de poder/saber que o marca historicamente, produzindo um tipo específico de visibilidade para o sujeito, para o sexo e sexualidade. Dessa forma, partimos da materialidade fílmica de "Reformatório das depravadas", um drama erótico dirigido em 1978 por Ody Fraga, para verificar, fílmico-discursivamente, como o corpo é atravessado por uma política disciplinar e de controle, no interior de um momento específico da história brasileira, que mobilizam e ventilam discursos acerca de um modelo ideal de sexualidade e políticas de vida. Este trabalho se insere nos estudos da Análise do Discurso de linha francesa, cuja principal contribuição são os postulados de Michel Foucault.

PALAVRAS-CHAVE: Corpo; Sexualidade; Segurança; Discurso; Foucault.

\section{Introdução}

Existe na sociedade, desde o século XVIII, uma política em torno dos corpos que tem consistido, como mostra Foucault (2008), em resolver os problemas sociais que, à época, na Europa, tratava-se inicialmente, ou em todo caso mais urgentemente, de questões

\footnotetext{
* Mestre em Linguística pela Universidade Estadual do Sudoeste da Bahia (Uesb).

** Professor Pleno da Universidade Estadual de Feira de Santana (Uefs). Doutor em Linguística e Língua Portuguesa pela Universidade Estadual Paulista Júlio de Mesquita Filho (Unesp) campus de Araraquara. Pós-doutor (PDE/CNPq) em Discurso, Corpo e Cinema na Sorbonne Nouvelle, Paris 3.
} 
ligadas à permanência e desenvolvimento das espécies em relação à saúde. Para que a saúde e, consequentemente, a garantia de vida fosse assegurada, a sociedade se viu obrigada, por meio de seus governos, a invocar estratégias que consistiam tanto em dispor melhor o espaço urbano quanto a forma como os doentes eram afastados do convívio com os demais ou como se administravam a morte (os cadáveres) e a doença, em potencial, que dali poderiam emergir. Nesse mesmo período, embora não concomitantemente, uma profusão de discursos enquanto cuidados em torno da sexualidade dos sujeitos começam a circular, conforme Foucault (1988) e, a partir daí, o sexo começa a figurar no centro de toda uma intervenção de segurança, segurança essa que consistia na administração das espécies através de um biopoder que se operava por meio da gestão da saúde, da natalidade, dos usos dos prazeres, da sexualidade de modo geral. É nesse contexto que o corpo se configura como um espaço ideal para intervenções diversas, que correspondem a toda uma aparelhagem que tem por finalidade esquadrinha-lo, observa-lo, diagnostica-lo, vigia-lo, tudo em nome da tentativa de confirmar a segurança da espécie. Não à toa a sexualidade dos adolescentes, como a masturbação, começa a ser vigiada, ou há toda uma campanha contra o incesto ou simplesmente uma divulgação exaustiva do casamento como formas de exercer uma sexualidade "sadia" para que o futuro das espécies pudesse descansar em leito tranquilo. Como afirma Foucault (1988, p. 27), "no século XVIII o sexo se torna questão de "polícia", não no sentido de se ter que reprimi-lo, proibi-lo, silenciá-lo, mas no sentido de se arrolar a ele um rigor e um alerta em nome de uma maior utilidade social. O sexo passa a ser policiado. E não só por uma polícia propriamente, braço operador de um discurso jurídico, mas pela igreja e por toda a sociedade. Todas essas questões acampam o cerne de um ideal de sociedade que aspira a um sucesso que só é possível visualizando em seu horizonte uma gestão calculada da sexualidade. Segundo Foucault (1988, p. 29),

É verdade que já há muito tempo se afirmava que um país devia ser povoado se quisesse ser rico e poderoso. Mas é a primeira vez em que, pelo menos de maneira constante, uma sociedade afirma que seu futuro e sua fortuna estão ligados não somente ao número e à 
virtude dos cidadãos, não apenas às regras de casamentos e à organização familiar, mas à maneira como cada um usa seu sexo. (FOUCAULT, 1988, p. 29)

Instala-se, dessa maneira, uma ortopedia social (FOUCAULT, 2013, p. 87) cujo ponto de partida para o tratamento é a sexualidade. Desde os colégios, no século XVIII, até os espaços civis, públicos ou privados, a sociedade começa a adquirir uma arquitetura propícia para a vigilância dos corpos. Um panoptismo sexual que inserirá, no corpo, as marcas de um constante controle que fará do sexo um intocável lugar, um lugar de obscura e mística verdade. Nesse sentido, esses espaços denotam não somente uma sociedade de controle e de disciplina, mas uma sociedade de segurança. Trazendo Foucault (2008, p. 16) para a discussão, esquematicamente nós teremos uma sociedade tripartite que exercerá a governamentalidade nos seguintes níveis: a soberania em relação ao território, a disciplina sobre o corpo dos indivíduos e a segurança sobre a população.

Dessa maneira, o corpo é pensado não como um lugar individual e íntimo, mas como uma engrenagem essencial que faz funcionar a sociedade. O corpo, objeto de segurança social, se torna uma superfície onde políticas múltiplas se desenvolvem para manter o bem-estar da sociedade: é nesse ponto que o corpo se torna, acima de tudo, um elemento indispensável de governabilidade. No final do século XVIII, com a Revolução Industrial e a "descoberta" do corpo como potencialidade produtiva, em termos capitalistas, esse resguardo e essa governamentalidade a qual nos referimos se intensifica ainda mais.

Obra de vigilância e de interferência, o corpo passa a figurar no centro de toda uma produção, tanto material quanto de saber. Este último é que nos interessa, na medida em ele se presta ao nosso intuito de encontrar na sexualidade, na vigilância e no poder formas de produção e circulação de discursos.

Assim, o intuito desse artigo é verificar, a partir de uma materialidade fílmica de 1978, como uma biopolítica é capaz de, discursivamente, emergir um ideal de corpo e de políticas de vida segundo as condições de existência para o sujeito em um momento sócio histórico específico, no nosso caso aqui, o final da década de 1970, momento que o país atravessava uma ditadura civil-militar, período que compreendeu os anos de 1964 até 1985. 
Portanto, nossa análise consiste em avaliar o corpo discursivamente em um período histórico da vida brasileira, para problematizar o tipo de visibilidade possível em meio a uma disciplinarização que visava a produzir um ideal de sujeito.

\section{Reformatório das depravadas: corpo, norma e controle.}

Inegavelmente vivemos em uma sociedade de controle. Mas esse controle só é certificado mediante uma vigilância, que por sua vez, procura verificar o estabelecimento de normas e de instituir um raio-X social, cuja preocupação assegura uma estrutura social uniforme, não no nível dos indivíduos, mas no nível de direitos e deveres que dão fundamento ao funcionamento regular de uma sociedade. Nesse sentido, é o corpo o espaço central de intervenção: corpo, corpo-espaço e corpo-população se configuram enquanto lugares onde uma ordem do discurso deverá sempre ser alcançada. Nesse contexto, a materialidade fílmica de Reformatório das depravadas, filme dirigido em 1978 por Ody Fraga, constitui um interessante exemplo, enquanto metonímia, para o funcionamento dessa sociedade de observação-controle.

No interior de uma escola de correção para moças de classe média que não conseguiram se adequar às normas preconizadas, principalmente, por seus estratos sociais de origem, a vigilância e a disciplina são rígidas e constituem elementos decisivos na pedagogização dos corpos. Deste modo, o reformatório, coordenado por uma diretora rigorosa, se torna o lugar para onde o olhar social irá confluir para se retirar de lá um saber não só sobre a transgressão, puramente, mas da transgressão enquanto mecanismo de reafirmação da norma, uma vez que uma existe para ratificar a outra.

Dessa maneira, essa materialidade fílmica, assim como inúmeras que fazem parte da assinatura da pornochanchada ou aquelas que se enquadram sob a classificação WIP (Woman in prison), mobiliza discursos em torno dos modos de subjetivação e formas de adequação do corpo consoante um poder que orienta a nossa constituição enquanto sujeitos. Esse poder, é importante frisar, só o é enquanto algo que produz saber. Na medida em 
que ele circula, não do alto de uma organização social, mas em trânsito livre entre os sujeitos, alguns saberes vão se reunindo em torno dos corpos e isso produz efeitos de verdade. Essa verdade das condutas, por assim dizer, só é perceptível e assimilável enquanto sujeição, não uma sujeição estática, como quer em análises que privilegiam a ideologia, mas uma sujeição móvel que permite a cada um dos sujeitos se encaixarem em um espaço onde força e resistência reconfiguram lugares e olhares. É importante encarar a sujeição não como algo cristalizado, mas como ponto de partida para uma pergunta essencial que devemos nos realizar, segundo Foucault (2015, p. 283), enquanto sujeitos:

[...] não perguntar por que alguns querem dominar, o que procuram e qual a sua estratégia global, mas como funcionam as coisas no nível do processo de sujeição ou dos processos contínuos e ininterruptos que sujeitam os corpos, dirigem os gestos, regem os comportamentos etc. (FOUCAULT, 2015, p. 283)

Nesse sentido, essa é uma das perguntas principais que nos guiam ao longo de toda a nossa proposta. Reconfigurando essa indagação, nos termos que nos interessa aqui, nós temos o seguinte questionamento: que tipo de vigilância e de segurança a materialidade fílmica de Reformatório das depravadas parece querer nos prognosticar? A resposta já foi dada no início do tópico, de modo superficial, mas é pungente nos aprofundarmos um pouco mais nessa questão.

O enredo de Reformatório das depravadas consiste em mostrar, no âmbito de uma instituição corretora para moças de classe média, o dia a dia de mulheres que não se encaixaram nas normas recomendadas por suas famílias, sendo relegadas a um tipo especial de educação, educação esta que gira em torno de valores cristãos e conservadores, uma vez que a instituição é dirigida por uma mulher austera e religiosa, que não mede esforços para inserir as alunas naquilo que a moral judaico-cristã, conservadora e burguesa, separou para a sexualidade e, principalmente, para as mulheres. A materialidade fílmica apresenta os ataques a um corpo que, historicamente, vem sofrendo silenciamentos. Ao confinar moças que não se encaixaram em uma norma esperada em micro sociedades (as famílias, por 
exemplo), a instituição corretora coloca diante de nós um debate sobre corpos utópicos que não conhecem o seu lugar no discurso e, por isso, causam uma fissura no mesmo: ao negar a adequação de uma sexualidade e de um modo de vida segundo os preceitos de uma moral conservadora e patriarcal, as mulheres produzem um discurso de resistência que vai de encontro com os princípios vigentes em uma sociedade em que ainda reina um tipo de hegemonia sexual em que as mulheres ocupam o lado social periférico. Temas como namoro proibido ou lesbianismo fazem parte do universo fílmico, tornando o ambiente e os corpos ali presentes um heterotópico lugar de sexualidades polimorfas que encontram precariamente possibilidade de manifestação na sociedade "normal".

Nesse contexto, identificamos, na materialidade fílmica, discursos de poder e de resistência que se revezam, ora para combater essas sexualidades "não autorizadas", ora para dar vazão às mesmas. Diante disso, ao partir da premissa de que a escola de punição funciona para combater essas "ilegitimidades" dos corpos, nos deparamos com um discurso conservador central que consiste em reafirmar a ideia de família enquanto origem do lugar de domínio, posse e controle do corpo: antes de adequado à sociedade, os corpos devem estar adequados em um núcleo menor, a família. Isso supõe uma ideia de pedagogia do corpo e da sexualidade de uma vida "interna" para uma "externa", assim como supõe uma moralidade para a sexualidade e para a vida do sujeito, de modo geral. Para Carlos Roberto Winckler (1983, p. 20),

[...] a família mantém a angústia sexual e o sentimento de culpa das massas oprimidas, suprimindo a capacidade crítica dos explorados. Ao introduzir a noção de que os filhos pertencem aos pais, ela cria as condições para que o indivíduo adulto aceite a autoridade do Estado e do Capital (WINCLER, 1983, p. 20).

Objeto irretocável e sagrado, segundo os preceitos judaico-cristãos e de uma moral conservadora, a família constitui o lugar de preservação e de resguardo por excelência. É a partir dela e em nome dela que temas como incesto, sexualidade precoce ou relação sexual fora do casamento constituirão assuntos da ordem da segurança, não somente segurança 
intrafamiliar, mas segurança da espécie, do trabalho e de uma moral. Para que isso fosse assegurado, eram bastante comuns, até o século XX, escolas e internatos para moças ou para rapazes. O ideal era que indivíduos do sexo oposto vivessem separados, seja da mesma família ou não, para que o corpo fosse amparado de investidas do desejo e para que a moral vigente fosse preservada. Obviamente esses tipos de escolas estavam reservadas apenas para as famílias mais abastadas, aquelas que possuíam um poder aquisitivo maior para aplicar, aos filhos, um tipo de educação específica.

No interior desses internatos, a educação era rígida e bastante normativa. Em Vigiar e Punir, Foucault (2013, p. 137) afirma que a disciplina - requisito fundamental para tornar os corpos dóceis - é alcançada da maneira mais plena, por exemplo, em colégios internos, assim como nos quartéis, onde há um princípio de cerca em que os internos, protegidos do mundo exterior, enclausurados em um espaço analítico que só reconhece suas leis e funcionamentos próprios, dão curso a uma educação mais homogênea.

Irradiava, no cerne desses centros, um poder que procurava arrancar dos corpos um saber que pudesse servir à norma a qual se julgava oficial; um poder que pudesse produzir, nesses corpos internos, um tipo de condicionamento à par de uma moral preconizada; um poder que pudesse mobilizar e perpetuar um discurso sobre sexualidade, corpo e família segundo um parâmetro preestabelecido.

Para que esses valores pudessem ser assegurados e impressos aos corpos, uma vigilância constante e ostensiva se instalou em torno deles. Para Joaquim Tavares da Conceição (2012, p. 153), nos internatos "Buscava-se educar pelo exemplo, mas também pela vigilância visando coibir condutas em desacordo com a moral". Freiras, padres, diretores, educadores ou bedéis, encarregados da regulagem desses corpos, funcionavam como panópticos móveis cujos olhares atentos estavam a serviço da normalização das condutas, normalização segundo uma ordem do discurso presente nesses ambientes. Nesse sentido, esses espaços caracterizam um lugar específico de poder e saber, na medida em que uma educação para o corpo é transmitida por meio de um confinamento e de um conjunto de práticas que fazem do corpo um objeto de escrutínio, de análise e de reparação. 
Nessas instituições de correção, o que se vê é o controle de uma moralidade, tendo o corpo como ponto material de inserção do poder: como bem demonstrou Foucault (2015), o corpo é a superfície onde o exercício do poder e a produção do saber se consolida. Não podemos pensar o poder separado do saber, isto é, o poder é a ferramenta para a produção do saber. Sem essa premissa, estaríamos nos valendo de uma análise muito comum entre os teóricos que se utilizam de uma noção verticalizada de poder, equiparandoo a noção de repressão e violência. Deste modo, é pungente pensarmos o poder como um requisito para o aparecimento de saberes e de resistências. No nosso caso, aqui, esses saberes se reúnem em torno do corpo no sentido de que algumas normas são criadas e geridas para o funcionamento de uma sociedade, como o controle da sexualidade pela natalidade, pelo casamento ou da masturbação; por outro lado, a instituição de um poder pressupõe uma resistência na medida em que, em seu bojo, opacamente, involuntariamente, imperceptivelmente, efeitos de inversão e de transgressão são iniciados.

Os controles da masturbação praticamente só começaram na Europa durante o século XVIII. Repentinamente, surge um pânico: os jovens se masturbam. Em nome desse medo foi instaurado sobre o corpo das crianças - através das famílias, mas sem que elas fossem a sua origem - um controle, uma vigilância, uma objetivação da sexualidade com uma perseguição dos corpos. Mas a sexualidade, tornando-se assim um objeto de preocupação e de análise, como alvo de vigilância e de controle, produzia, ao mesmo tempo a intensificação dos desejos de cada um pelo próprio corpo. (FOUCAULT, 105, p. 236)

Adiante, como dito anteriormente, não podemos ignorar o corpo enquanto instrumento para a produção de riquezas. A questão que circunda a preservação do corpo para servir a uma moral conservadora ou para, supostamente, prevenir a espécie de males em torno da saúde não se encerra aí: temos, do mesmo modo, como pano de fundo, o germe de uma consciência econômica que direciona, inclusive, a vida íntima dos sujeitos. O advento do homo oeconomicus fez reunir, em torno do corpo, uma ideia dele enquanto ferramenta para a qual se deveria lançar direitos e deveres para a sua prevenção, ou melhor, para 
assegurar que um potencial produtivo não fosse corrompido. Conforme Foucault (2015, p. 286),

[...] já que o corpo humano se tornou essencialmente força produtiva, a partir dos séculos XVII e XVIII, todas as formas de desgastes irredutíveis à constituição das forças produtivas - manifestando, portanto, a própria inutilidade - foram banidas, excluídas ou reprimidas. (FOUCAULT, 2015, p. 286)

Nesse contexto, a questão que perpassa a iniciativa de resguardar o corpo está arrolada a toda uma economia do poder que faz dele um território "sagrado" em função do que ele desempenha ou pode desempenhar, nos mais diversos níveis. Discursivamente, não estamos diante somente de uma moral judaico-cristã que atribui aos corpos um direcionamento transcendental, mas estamos diante, antes e sobretudo, de uma moral que, de forma subjacente, inconsciente, visa atribuir ao corpo uma importância que ele possui enquanto engrenagem social: é necessário que os corpos estejam em funcionamento conveniente, segundo uma norma, para que a sociedade funcione adequadamente.

Diante desse quadro, é natural que em torno dos corpos alguns olhares institucionais atentos acompanhem seu trajeto e sua performance. Seja na escola, na fábrica, na empresa, na igreja ou simplesmente dentro de casa, no seio familiar. O corpo é a superfície, por excelência, onde os olhares sociais irão se confluir. A medida dos atos, o cálculo dos gestos, a equação do poder ou inteligibilidade das moralidades terão no corpo um equivalente físico capaz de dizer quem somos ou como estamos, por isso um intenso escrutínio anátomo-político para preservar aquilo que é considerado não um bem particular, somente, mas um órgão social.

Abaixo, nós temos um grupo de fotogramas que fazem parte do encadeamento fílmico de Reformatório das depravadas. Os movimentos da câmera, por exemplo, produzem esse efeito de vigilância constante acerca do corpo o qual nos referimos. Ao aparecer, na materialidade fílmica, uma multiplicidade de lugares estratégicos onde as câmeras estão localizadas, nós temos a ideia de que o corpo não somente é vigiado o tempo inteiro, mas avaliado, invadido, medido e, posteriormente, julgado. 
Figura 1 - Fotogramas retirados do filme "Reformatório das depravadas".

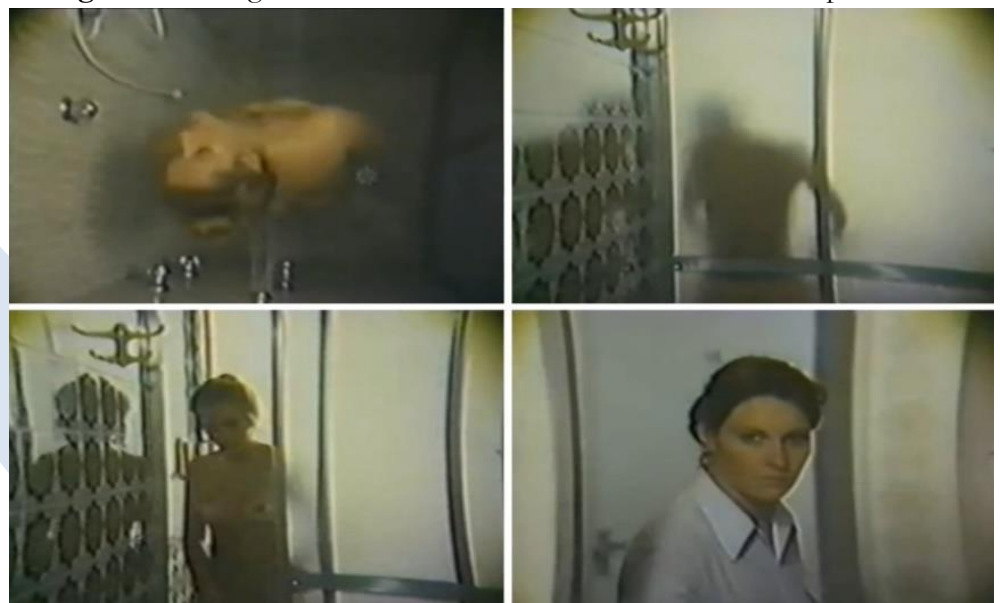

Fonte: REFORMATÓRIO DAS DEPRAVADAS. Direção: Ody Fraga. Produção: Antônio Polo Galante. São Paulo: Titanus Filmes; Ouro Filmes; Fama Filme S.A., 1978. $82 \mathrm{~min}$, Eastmancolor, Som, Cor. Formato: $35 \mathrm{~mm}$.

Do primeiro plano, onde há uma plongée absoluta (câmera alta localizada em um vértice do objeto filmado), ao último, onde há uma câmera frontal, coincidindo com a imagem da bedel que vigia as internas, temos nesse estrato a ilustração de um movimento de câmera que, à par da natureza do nosso objeto de análise, constitui o recurso por excelência para a produção dessa ideia de vigilância ostensiva direcionada aos corpos, fato que produz um tipo de discurso em torno do corpo em que uma atenção onipresente e onisciente nos acompanha o tempo inteiro. Essa atenção onipresente e onisciente nada mais é do que a norma, a norma que nos persegue e que visa nos inserir em sistemas de utilidade e segundo um funcionamento julgado socialmente adequado. 
Figura 2 - Fotogramas retirados do filme "Reformatório das depravadas".

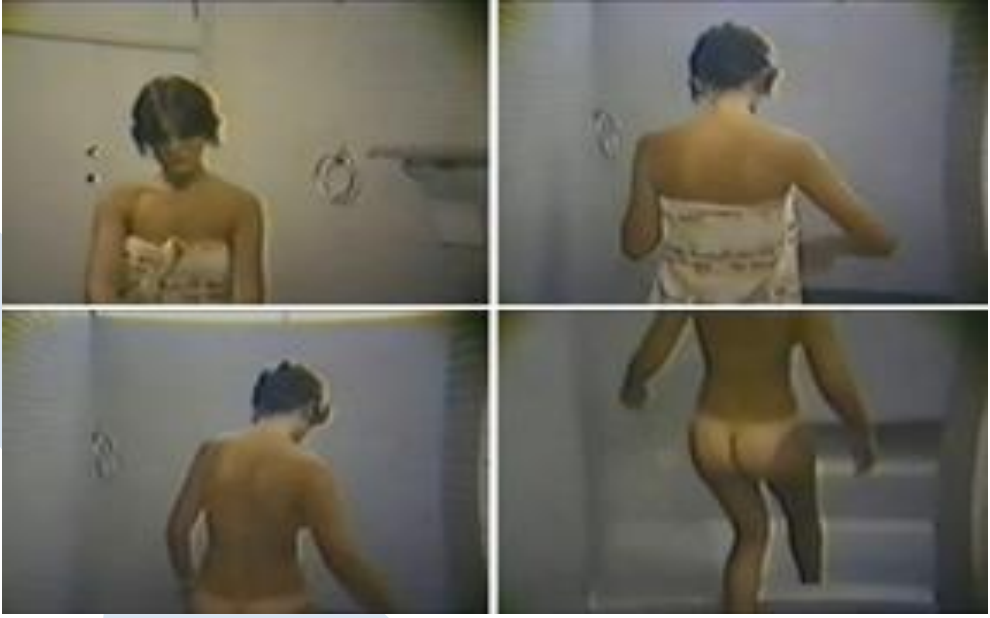

Fonte: REFORMATÓRIO DAS DEPRAVADAS. Direção: Ody Fraga. Produção: Antônio Polo Galante. São Paulo: Titanus Filmes; Ouro Filmes; Fama Filme S.A., 1978. $82 \mathrm{~min}$, Eastmancolor, Som, Cor. Formato: $35 \mathrm{~mm}$.

Figura 3 - Fotogramas retirados do filme "Reformatório das depravadas".
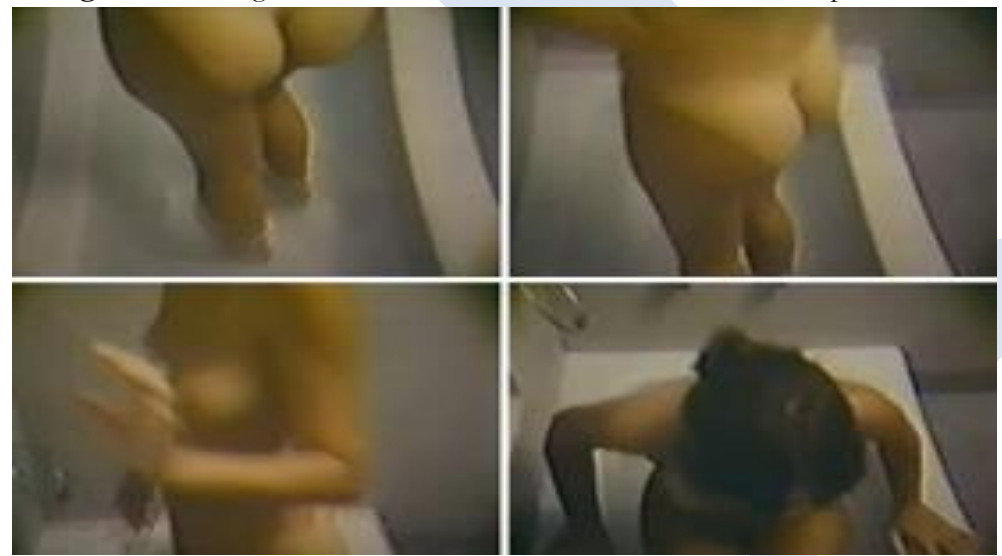

Fonte: REFORMATÓRIO DAS DEPRAVADAS. Direção: Ody Fraga. Produção: Antônio Polo Galante. São Paulo: Titanus Filmes; Ouro Filmes; Fama Filme S.A., 1978. $82 \mathrm{~min}$, Eastmancolor, Som, Cor. Formato: $35 \mathrm{~mm}$. 
Acima, as figuras 2 e 3 nos auxiliam a pensar a respeito desse rigor vigilante como modos de nos remeter a um panoptismo onipresente. Assim como a figura 1, as figuras 2 e 3 constituem sequências de fotogramas oriundas de Reformatório das depravadas, sequências essas que correspondem a uma situação vivenciada em um banheiro, no qual uma das reformadas da instituição realiza seus momentos de banho e higiene pessoal. Ao ser flagrada por uma câmera que acompanha todas as medidas do seu corpo, a interna possui diante de si um olhar interminável que prestará atenção aos seus atos até nos momentos mais improváveis, tendo sua privacidade violada em nome da segurança de um corpo que não pode fugir da utilidade social que ele carrega em si. O movimento da câmera, ao longo dos oito planos que compõe as figuras 2 e 3 , destaca anatomicamente o corpo da mulher e sua relação com aquele espaço, reforçando a ideia de uma privacidade transgredida em nome de uma garantia para a sociedade e para família em função daquilo que o corpo representa para a manutenção de interesses diversos que movimentam a dinâmica das sociedades. Ao capturar, em partes, o corpo se despindo e se dirigindo para o seu momento íntimo de assepsia, a câmera coloca diante de nós, sujeitos-espectadores, uma condição real que existe acerca dos nossos corpos, condição que faz da nossa intimidade e dos nossos corpos territórios onde não há nada que possamos declarar autenticamente nosso: nossos corpos utópicos são sempre invadidos pelo outro e é isso que nos torna sujeitos. Além disso, o movimento da câmera perscruta o corpo de tal modo que uma ideia de direito ao corpo e ao sexo se desloca do interno para o externo, do privado para o público, ressaltando nosso sexo como objeto de análise e de avaliações sociais: o olhar voyerista da câmera (que é o nosso olhar, que é o olhar da norma) faz de pedaços de corpo objetos de observação e gerenciamento.

A partir desses estratos fílmicos, as figuras 1, 2 e 3, nos deparamos com um juízo acerca da sexualidade enquanto algo sempre propenso à contemplação e à advertência aos corpos. Não à toa, nesses dois estratos (assim como ao longo de todo o filme), as situações de vigilância são todas referentes a corpos nus, como se a sexualidade vasculhada dos sujeitos, nesse caso das mulheres detidas, fosse o objeto central para esse cuidado. 
Como mostra Foucault (1988, p. 27), o sexo não é apenas julgado, mas administrado. Há, em torno dele, uma gama de procedimentos que fará com que um princípio de utilidade pública seja alcançado, o sexo deve ser regulado para que um padrão ótimo de funcionamento beneficie a todos. Isso implica em fazer do sexo um constante elemento de análise, para que o mesmo alcance, cada vez mais, as formas legítimas segundo as quais se esperam na sociedade, onde determinados valores e morais são rechaçados ou legitimados. É por isso que, como afirma Foucault (1988, p. 27), a partir do século XVIII um princípio de policiamento se instala ao redor do corpo.

Toda esta atenção loquaz com que nos alvoraçamos em torno da sexualidade, há dois ou três séculos, não estaria ordenada em função de uma preocupação elementar: assegurar o povoamento, reproduzir a força de trabalho, reproduzir a forma das relações sociais; em suma, proporcionar uma sexualidade economicamente útil e politicamente conservadora? (FOUCAULT, 1988, p. 37-8)

Essa polícia do corpo e do sexo é exercida em sua forma máxima através de uma vigilância que sinaliza uma segurança: segurança da espécie, das forças de trabalho, do funcionamento dito adequado de uma sociedade que, desde então (século XVIII) passa a ser regida por uma mentalidade balizada pelo capital e pelo que ele representa socialmente. É nesse sentido que esse poder dispensado aos corpos, sob forma de vigilância ou advertência, na ótica foucaultiana, é positivo, pois não pode ser encarado como manifestações coercitivas ou de repressão, mas como instrumento capaz de mobilizar saberes.

Abaixo, mais uma vez, essa ideia de panoptismo nos é revelada a partir da observação que há em torno do corpo, dispensada pela diretora da escola de correção a uma das internas do estabelecimento. Interessante notar, além disso, que o movimento da câmera, que gira ao redor dos corpos, nos três primeiros planos, e depois, em um movimento vertical, nos dois últimos planos, produz uma leve contraplongée (câmera de baixo para cima), recurso que permite pensarmos, em termos de efeitos fílmicos-discursivos, mais uma vez, no corpo enquanto objeto de exame, análise, adequação e submissão a uma hierarquia. 
Figura 4 - Fotogramas retirados do filme "Reformatório das depravadas.

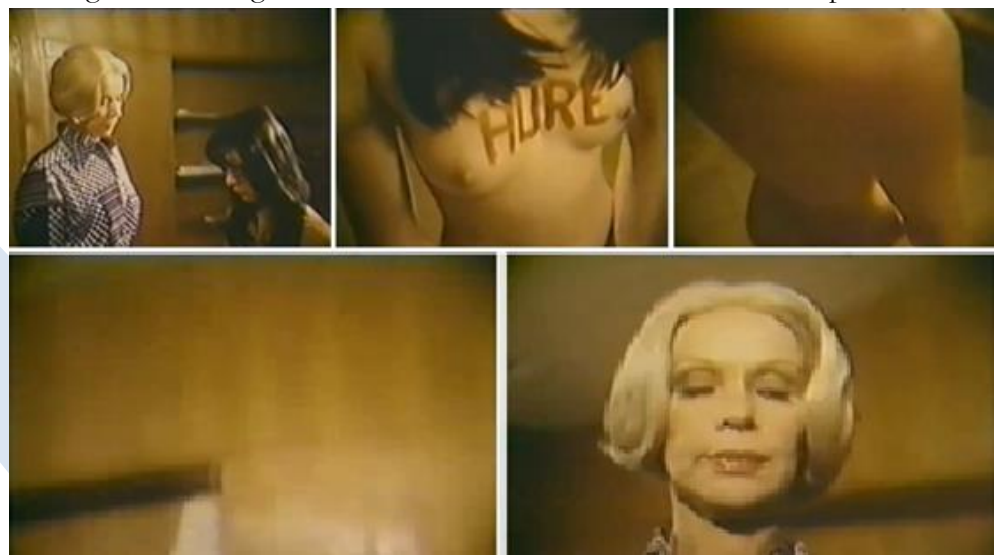

Fonte: REFORMATÓRIO DAS DEPRAVADAS. Direção: Ody Fraga. Produção: Antônio Polo Galante. São Paulo: Titanus Filmes; Ouro Filmes; Fama Filme S.A., 1978. $82 \mathrm{~min}$, Eastmancolor, Som, Cor. Formato: $35 \mathrm{~mm}$.

Na História da sexualidade 1 - a vontade de saber, Foucault (1988) nos ensina que um dos maiores mecanismos de extração da verdade do ser é a confissão. Em Reformatório das depravadas, a partir de uma vigilância devotada e peremptória, o corpo se submete a um tipo de confissão constante para arrancar dele não somente a verdade de seu ser, mas para fazer dele um artefato apropriado segundo uma norma. Com isso, estamos diante de um princípio de adestramento do corpo para fazer dele um elemento disponível e adequado socialmente. Essa é a forma da disciplina, estágio final do poder, na ótica foucaultiana. “A disciplina "fabrica" indivíduos; ela é a técnica específica de um poder que toma os indivíduos ao mesmo tempo como objetos e como instrumentos de seu exercício”. (FOUCAULT, 2013, p. 164)

\section{Conclusão}

Nosso objetivo com esse artigo foi problematizar o corpo em um momento específico da vida brasileira, a partir de um corpus cuja natureza, julgamos, possui o potencial de reunir a historicidade, a cultura, as tenções, os discursos e as políticas de vida dos sujeitos 
em um país em particular, nesse caso o Brasil, discursivizadas em imagens. Diferente da avaliação de um espectador comum e despropositado, as pornochanchadas funcionam como um material rico para a análise em torno dos corpos e de suas visibilidades no momento da história que compreende a década de 1970 até início da década de 1980, material esse capaz de nos mostrar o percurso do corpo na cadeia da avaliação social ao longo dos tempos.

A partir de Reformatório das depravadas, filme de 1978 dirigido por Ody Fraga, constatamos que a vigilância não só é essencial para manter o controle, mas que ela própria (a vigilância) é o controle: um controle que acompanha os corpos para retirar deles o máximo potencial de assujeitamento às normas que são a substância para o estabelecimento de uma sociedade disciplinar.

À priori, incompreendida e maldita, os filmes que compõem a assinatura do que ficou conhecido por pornochanchada causaram (e continuam causando) choque e incômodo a certa parcela da sociedade que insiste em atribuir a esse tipo de entretenimento um juízo de valor depreciativo e precipitado, uma vez que ela, a pornochanchada, foi e continua sendo, para muitos, um período fílmico que contribuiu para o enfraquecimento e para a transgressão de uma moral conservadora e cristã, além de um suposto declínio cultural sustentado pelas massas populares que consumiam este tipo de entretenimento em salas de cinemas ao redor do país.

Entretanto, em contato íntimo com essas materialidades fílmicas, o que verificamos é que, de forma discursivizada, essas películas nada mais fazem do que reafirmar a moral vigente e os valores sociais que atravessavam o momento histórico da época. Reformatório das depravadas, um produto do seu tempo, portanto, não tem nada de transgressor, ao contrário, de forma discursiva ela nos coloca em uma conexão direta com a norma e o modelo disciplinado dos corpos, ela funciona como um dispositivo capaz de ventilar, para aqueles que a observam, um paradigma de corpo e sexualidade, um padrão de subjetividade e políticas de vida que só encontram inteligibilidade e sustentação de acordo com a sociedade normalizadora. 


\section{SEXUALITY, SAFETY AND DISCIPLINE: BODY AND DISCOURSE IN ODY FRAGA'S “REFORM OF THE DEPRAVED” (1978)}

Abstract: Our aim, with this article, is to problematize the body in the midst of the power / knowledge relations that mark it historically, producing a specific type of visibility for the subject, for sex and sexuality. Thus, we start from the filmic materiality of Reform of the depraved, an erotic drama directed in 1978 by Ody Fraga, to verify, filmically and discursively, how the body is crossed by a disciplinary and control policy, within a specific moment of brazilian history, which mobilize and ventilate discourses about an ideal model of sexuality and life policies. This work is part of the studies of French Discourse Analysis, whose main contribution are the postulates of Michel Foucault

KEYWORDS: Body; Sexuality; Power; Discourse; Foucault.

\section{REFERÊNCIAS}

CONCEIÇÃO, J. T. Internar para educar. Colégios-internatos no Brasil (1840-1950). Tese

(Doutorado em História) - Faculdade de Filosofia e Ciências Humanas, Universidade Federal da Bahia, Bahia. 2012.

FOUCAULT, M. História da sexualidade 1 - a vontade de saber. Trad. de Maria Thereza da Costa Albuquerque e J. A. Guilhou Albuquerque. Rio de Janeiro: Graal, 1988.

. Segurança, Território, População. São Paulo: Martins Fontes, 2008.

. Vigiar e Punir. Nascimento da prisão. Trad. de Raquel Ramalhete. 20ª Ed. Petrópolis: Ed. Vozes, 2013.

. Microfísica do poder. São Paulo: Paz e Terra, 2015.

REFORMATÓRIO das depravadas. Direção: Ody Fraga. Produção: Antônio Polo Galante. São Paulo: Titanus Filmes; Ouro Filmes; Fama Filme S.A., 1978. 82 min, Eastmancolor, Som, Cor. Formato: $35 \mathrm{~mm}$

WINCKLER, Carlos Roberto. Pornografia e sexualidade no Brasil. Porto Alegre: Mercado Aberto, 1983.

Recebido em: 31/08/2019. Aprovado em: 16/01/2019. 